\title{
Open Innovation towards Individual Innovation Capability: Tacit Knowledge Perspective in Indonesian Small and Medium Industries (SMI)
}

\author{
Augustina Asih Rumanti, T.M.A. Ari Samadhi, Iwan Inrawan Wiratmadja, and Indryati Sunaryo
}

\begin{abstract}
This research is based on an issue that tacit knowledge is a crucial asset to create an innovation. The development of innovation process is now changing from close innovation to open innovation. Open innovation is one way that can be done to improve the ability to innovate an organization. In open innovation the knowledge used to innovate can be obtained from the external and internal organization, both in large scale organization, medium scale and small scale. Open innovation enables organizations such as SMI to innovate their ability by adopting knowledge from outside the organization, internalizing and then transferring knowledge to other organizations with similar scale and type of business. Knowledge that moves on open innovation consists of explicit knowledge, implicit knowledge and tacit knowledge. Tacit knowledge management is relatively more difficult than explicit knowledge management. This happens because the tacit knowledge is abstract, attached to the individual, and its existence is not fully realized.

Innovation is an important factor for a company to survive in economic competition. Therefore, this research has aims to analyze the correlation between tacit knowledge and individual innovation capability to open innovation. This research is done by doing a case study at SMI. Simulation result using PLS show a strong correlation between tacit knowledge and open innovation towards individual innovation capability. This result is caused by the lack of company's concern to individual tacit knowledge which leads to the problem of individual tacit knowledge codification that is used for doing open innovation in SMI
\end{abstract}

Index Terms-Tacit knowledge, intellectual capital, innovation.

\section{INTRODUCTION}

In recent economic situation, competition between companies production similar products is growing steadily fiercer. This situation makes the strong correlation between economic growing and innovation. Innovation becomes an important factor for the company to produce high quality product which adheres to customers' needs. There are some Theories that identified the meaning of innovation. Innovation consisted of five types. Those types are: (1) introduce new products and qualitative changes of current products, (2) introduce new process into industry, (3) create new market, (4) develop new source of raw material or other input, and (5) change in industrial organization. In short, innovation is not just creating new things but creating a level

Manuscript received February 13, 2018; revised May 5, 2018.

The authors are with Departement of Industrial Engineering, Bandung Institute of Technology, Indonesia and Department of Industrial Engineering, Telkom University, Indonesia (email: augustinaar@gmail.com asamadhi@mail.ti.itb.ac.id, iwan@1spitb.org, rya_ryo@yahoo.com). of improvement between one entity and its previous version. [1].

From those definitions of innovation, innovation is one of important indicators for the company or organization to survive in heavier economical competition. In order to improve their ability, company has to create an innovation within organization, for example product innovation, method, or market share. Outputs of engineering division at SMI are affected by individual factors who work in that division.

The crucial individual factor that has a strong correlation with organizational innovation is knowledge although that correlation between tacit knowledge and its complex to explain. Knowledge becomes a dominant factor in production process to give added value into product. The definition of knowledge is something unique as information and data. Individual knowledge transformed into a new product and service or modified product and service [2]. Knowledge can be divided into two parts, individual knowledge that could be formally dispersed (explicit knowledge), for example: financial report and human resource data, and individual knowledge that is difficult to be communicated (tacit knowledge), for example: working experience, skills, and information knowledge. Because of its character, organization has to focus on tacit knowledge in product development process. These focuses can be knowledge management system within organization, so knowledge that is difficult to be communicated (tacit knowledge) especially individual tacit knowledge can be developed to make an innovative organization.

\section{LITERATURE REVIEW}

\section{A. Tacit Knowledge}

Tacit knowledge is used to describe a type of human knowledge that is hard to articulate to express in its fullness. That is to say, one obvious characteristic of tacit knowledge is its defiance when described in words. Tacit knowledge is practical know-how that one picks up on a job or in everyday kinds of situation, rather than through formal instruction. When decided by the ownership of knowledge, tacit knowledge can be divided into two types which are [3]:

\section{1)Organization tacit knowledge}

Pick up on team work and team spirit that formed within a team.

\section{2)Individual tacit knowledge}

Formed by experience individually and skills. This type also can be separated into two types: cognitive tacit knowledge such as individual value, and special skill which 
deals with emotion, technique, professional skill, and so on.

Individual tacit knowledge has its own specialty. Different people have different tacit knowledge and they perhaps have not the same tacit knowledge in the same workshop. Individual tacit knowledge can increase individual benefits because it is related to someone's work performance. Individual tacit knowledge can be classified into [4]:

- General tacit knowledge is used in all kinds of work and circumstances which can satisfy a series of work

- Special tacit knowledge means the tacit knowledge which is only used under special work and hard to transform under different work and situation.

\section{B. Open Innovation}

Innovation is crucial to the success and survival of companies. Innovation is a process when a company identified its own problems and get the new solutions (in this case, new knowledge) to solve those problems [5].

The main reason for innovation activity is to build up market share and ensure/increase the profitability of the company in order to protect the future independence of the company. However, innovation is often confused with invention. Invention is manifestation of a idea. In contrast, innovation happens when ideas are applied successfully in practice/adoption [6]. Adoption process becomes a must for the company to keeping the next process innovation.

Different type of innovation can be delivered, for example it may be a product, a process, or an organizational innovation. The scope of innovation can range in scope from radical/disruptive to incremental/evolutionary innovation. Depending on type, complexity and scope, the role of knowledge in the innovation process is crucial. For more radical innovations, new knowledge needs to be created or applied from very different contexts. For incremental innovations, it is more important to re-use existing knowledge in many aspects of the product's design, manufacture, and delivery. Various mechanisms exist to deliberately feed new knowledge into the organization, for example communities of practice, the reading of technical journals, conversations with customer and suppliers [7].

Open innovation uses inflows and outflows of knowledge system to accelerate internal innovation and expand the market for external use of innovation. Open innovation is a paradigm that assumes that organizations can take advantage of ideas from internal and external organizations [8].

The development of the innovation process is now changing from close innovation to open innovation [9]. Open innovation is one way that can be done to improve the ability to innovate an organization. In open innovation the knowledge used to innovate can be obtained from the external and internal side of the organization, both in large scale organization, medium scale and small scale [9].

Open innovation enables organizations such as IKM to innovate better by adopting knowledge from outside the organization, internalizing and then transferring knowledge or sharing knowledge to other organizations with similar scale and type of business. Knowledge that moves on open innovation consists of explicit knowledge, implicit knowledge and tacit knowledge [10]. Tacit knowledge management is relatively more difficult than explicit knowledge management [11]. This happens because the tacit knowledge is abstract, attached to the individual, and its existence is not fully realized [10], [12]. In this study the concept and definition of open innovation is the system of inflows and outflows of knowledge with the aim to accelerate internal innovation and expand the market through the use of external innovation where the knowledge used can be used to innovate both from the external and internal organization [8] 9].

In small and medium industries the existence of open innovation process is able to provide a better organizational change system, which is increasing cooperation, increasing knowledge of organization member and ability understanding of market condition. Implementation of open innovation requires enormous energy because it affects organizational culture factors, including aspects of human, organization and technology [13].

\section{RESEARCH METHODOLOGY}

\section{A. Model and Hypotheses in Research}

There are several indicators of tacit knowledge, adopted from previous research [14]: experience, interaction process, community, situation, informal condition, target oriented, transfer knowledge, environmental condition. The hypotheses of this study from research model are:

H1: Tacit knowledge has positive influence individual innovation capability.

$\mathrm{H} 2$ : Individual innovation capability has positive influence towards open innovation.

\section{B. Research Strategy}

A case study was conducted for this research. Analysis was conducted on individuals working in the engineering division for the company under research.

The study was done in an automotive company in Indonesia, as innovations in manufacturing process could be well articulated in companies of this type. We choose SMI because of its fast dynamic changes and the tough competition encountered in this particular business segment. Knowledge is crucial to survive in heavy economic competition. Tacit Knowledge variables have some indicators that obtained from previous study [8]. The variables is experience, personal interaction, community, situation, condition, transfer knowledge, target oriented, and informal. For Individual Innovation Capability there are four there are experience, situation, technology changes and knowledge [14]. For Open Innovation, the variables come from previous study there development planning, technology and $\mathrm{R} \& \mathrm{D}$, production, market, distribution/marketing, venture, networking, partnership and service [15]. The hypothesis for this research is shown at Fig. 1, for the first hypothesis is between tacit knowledge and individual innovation capability and the second hypothesis is individual innovation capability and open innovation. 


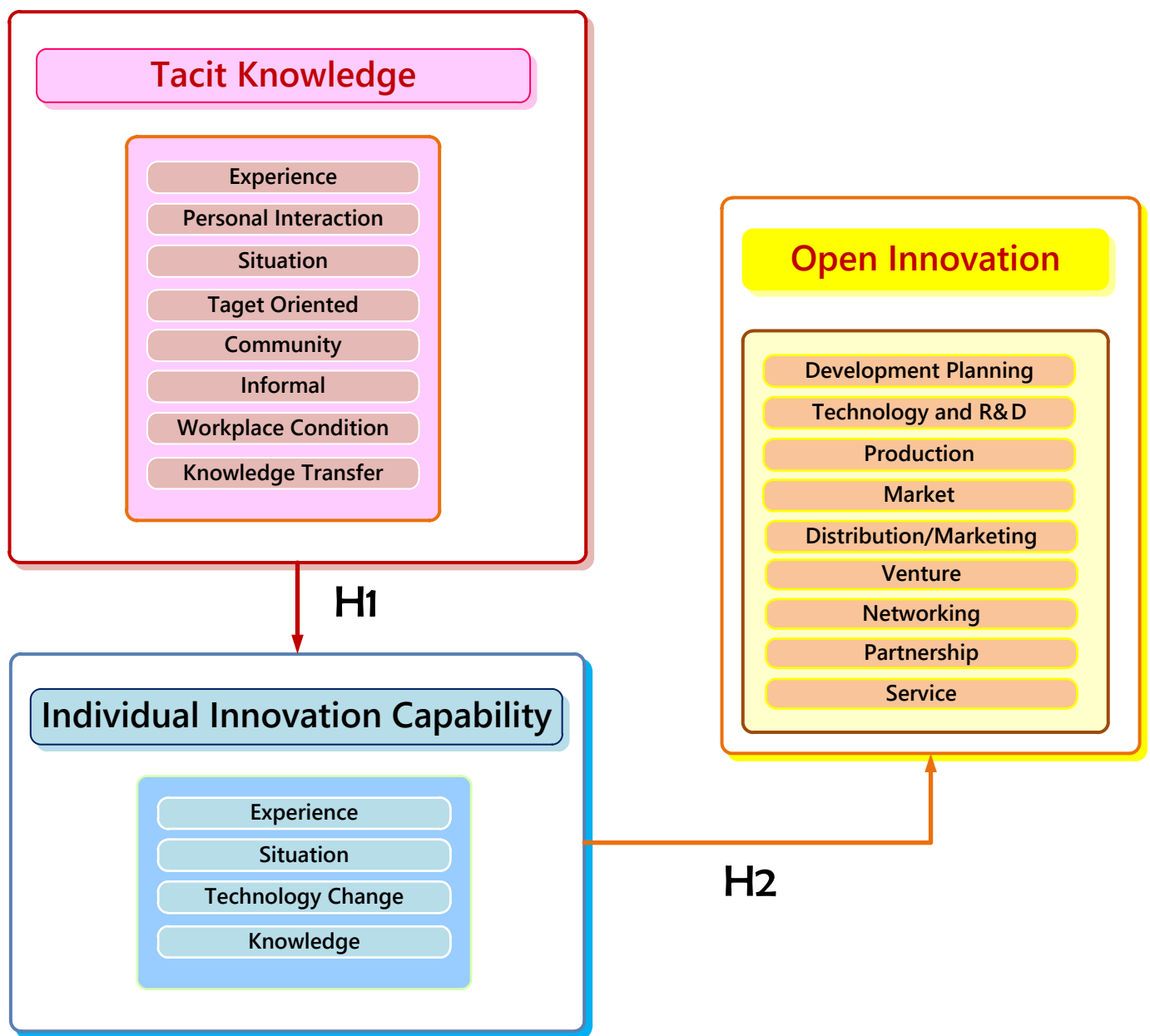

Fig. 1. Research model.

\section{ANALYSIS}

\section{A. Measurement Validation Analysis}

Validation of the measuring instrument uses two parameters: the value of the loading factor and cross loading. An indicator as valid if it has a loading factor value above 0.5 but in this study the initial calculation, there are several indicators that have a factor loading values below 0.5 . The indicators that have a factor loading values below 0.5 are considered not appropriate to measure latent variables so that this indicator be discarded and re-calculation. After revising II it can be seen that all the indicators already have a factor loading values above 0.5 .

Next validation measuring instrument can be seen from the cross loading where the value of cross loading an indicator should be higher than the value of cross loading other indicators in order to be valid. Differences of cross loading the loading factor is the value of cross loading shows a comparison of an indicator to measure the construct than used to measure other constructs. From the data processing is known, there are several indicators that have a value in a variable cross loading its manifestation is smaller when compared with the value of the other manifest variables indicators that have value in the variable cross loading its manifestation is smaller when compared with the value of the other manifest variables omitted as not precisely measure its manifestation variables and should be re-calculation, but because of there are several variables manifest that gone if we do the re-calculation and can change the whole model, so in this research just want to do fitting model and didn't do the re-calculation.

There are many indicators used to measure variables invalid manifest this can be caused by items of statements made to an indicator variable cannot explain its manifestation and can also be caused by people who responded to the questionnaire do not understand the purpose of the statements contained in the indicator so that one of the interpret the statement.

\section{B. Reliability Analysis of Research Variables}

The reliability of this research seen from the AVE (Average Variance Extracted) and CR (Composite Reliability) of output data processed using software Smart PLS 2. A said to be reliable if the variable has a value above 0.5 AVE and $\mathrm{CR}$ values above 0.7 . In this study the value AVE and CR there are several values below 0.5 (for the AVE) and below 0.7 (for CR) so that it can be said of all the variables used in this study has not been reliable and has good reliability, this is because of at the stage of validation, there are several indicators that didn't pass for factor loading and cross loading and that make the indicator not reliable and valid.

\section{Result from PLS Computation}

The data used in this research was obtained by questionnaire and calculated with statistic software called SEM Partial Least Square (SEM PLS). The data computed by using Partial Least Square (PLS) stated that tacit knowledge did not have influence towards innovation, but tacit knowledge had a positive influence towards individual innovation capability at SMI [16]. External validation 
showed that innovation in the company was not affected by tacit knowledge due to the company's lack of concern.

The most affected indicator of tacit is interaction process between persons who work in the company. Interaction process within the company makes enables knowledge transfer from one person to another, but this kind of knowledge is still hard to be communicated (explicit knowledge). Tacit knowledge just becomes a value esteem to someone because this knowledge cannot be used within company explicitly. Table I shows the results of data computation using Partial Least Square (PLS):

TABLE I: STASTISTICAL DATA PLS

\begin{tabular}{|c|c|c|c|c|c|c|c|}
\hline $\begin{array}{l}\text { Endogen } \\
\text { Construct }\end{array}$ & Exogenous Construct & Mean & AVE & $\mathrm{CR}$ & Weight & T-Statistic & Significantly \\
\hline \multirow{8}{*}{ 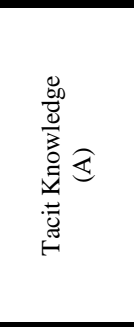 } & Experience (A1) & 3,32 & 0,62 & 0,51 & 0,07 & 3,39 & $\sqrt{ }$ \\
\hline & Interaction process (A2) & 3,82 & 0,69 & 0,73 & 0,46 & 3,92 & $\sqrt{ }$ \\
\hline & Community (A3) & 4,02 & 0,58 & 0,87 & 0,56 & 4,54 & $\sqrt{ }$ \\
\hline & Environmental condition (A4) & 3,55 & 0,60 & 0,82 & 0,23 & 2,69 & $\sqrt{ }$ \\
\hline & Transfer knowledge (A5) & 3,48 & 0,56 & 0,80 & 0,48 & 3,94 & $\sqrt{ }$ \\
\hline & Situation (A6) & 3,48 & 0,52 & 0,86 & 0,30 & 3,13 & $\sqrt{ }$ \\
\hline & Target oriented (A7) & 3,61 & 0,62 & 0,79 & 0,09 & 3,33 & $\sqrt{ }$ \\
\hline & Informal (A8) & 2,95 & 0,89 & 0,81 & 0,15 & 3,20 & $\sqrt{ }$ \\
\hline \multirow{4}{*}{ 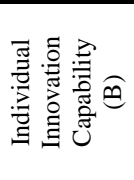 } & Experience (B1) & 3,16 & 0,63 & 0,80 & 0,24 & 6,32 & $\sqrt{ }$ \\
\hline & Situation (B2) & 3,27 & 0,72 & 0,55 & 0,12 & 4,72 & $\sqrt{ }$ \\
\hline & Technology changing (B3) & 3,62 & 0,51 & $\mathbf{0 , 8 1}$ & 0,41 & $\mathbf{8 , 9 7}$ & $\sqrt{ }$ \\
\hline & Knowledge (B4) & 3,64 & 0,50 & 0,77 & 0,19 & 7,11 & $\sqrt{ }$ \\
\hline \multirow{9}{*}{ 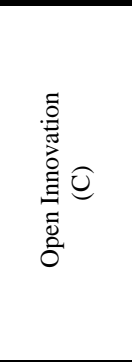 } & Development planning $(\mathrm{C} 1)$ & 4,11 & 0,69 & 0,65 & 0,15 & 6,29 & $\sqrt{ }$ \\
\hline & Technology and R\&D (C2) & 3,64 & 0,81 & 0,76 & 0,24 & 7,73 & $\sqrt{ }$ \\
\hline & Production $(\mathrm{C} 3)$ & 3,39 & 0,70 & 0,66 & 0,22 & 5,65 & $\sqrt{ }$ \\
\hline & Market $(\mathrm{C} 4)$ & 3,41 & 0,59 & 0,71 & 0,37 & 3,61 & $\sqrt{ }$ \\
\hline & Distribution/Marketing (C5) & 3,61 & 0,62 & 0,63 & 0,23 & 5,82 & $\sqrt{ }$ \\
\hline & Venture (C6) & 3,61 & 0,57 & 0,69 & 0,21 & 4,89 & $\sqrt{ }$ \\
\hline & Networking (C7) & 3,92 & 0,66 & $\mathbf{0 , 8 1}$ & 0,43 & 6,99 & $\sqrt{ }$ \\
\hline & Partnership (C8) & 3,88 & 0,74 & 0,78 & 0,35 & 5,23 & $\sqrt{ }$ \\
\hline & Service (C9) & 3,90 & 0,61 & 0,69 & 0,21 & 4,87 & $\sqrt{ }$ \\
\hline
\end{tabular}

\section{Variability Analysis of Research Model}

Variability research model can be seen from the R-square value. R-Square value can be seen in Table II below.

TABLE II: R-SQUARE VALUE

\begin{tabular}{|c|c|}
\hline TABLE II: R-SQUARE VALUE \\
\hline Dependent Variable & $R$ - Square \\
\hline Tacit Knowledge & 0,985 \\
\hline $\begin{array}{c}\text { Individual Innovation } \\
\text { Capability }\end{array}$ & 0,888 \\
\hline Open Innovation & 0,998 \\
\hline
\end{tabular}

R-square values of the Tacit Knowledge is at 0,985 which means the variance that can be explained by its manifestation variable is equal to 98,5 and $1,5 \%$ is explained by other factors. R-square for Individual Innovation Capability is at 0,888 which means the variance that can be explained by its manifestation variable is equal to $88,8 \%$ and $11,2 \%$ is explained by other factors and R-square for Open Innovation is at 0,998 which means the variance that can be explained by its manifestation variable is equal to $99,8 \%$ and $0,02 \%$ is explained by other factors.

\section{E. Research Hypothesis Analysis}

Result testing the hypothesis of this research, can be seen from the value of t-statistic resulting from the path on the coefficient of. A limit for this research is worth $\pm 3,182$ with the value of $\mathrm{v}=3$ and $\alpha / 2=0,0025$, if the value in range \pm 3,182 , will result accept $\mathrm{H}_{0}$ received and rejected $\mathrm{H}_{1}$, but if above $\pm 3,182$ will result accept $\mathrm{H}_{1}$ and $\mathrm{H}_{0}$ rejected.
This research has two main hypotheses, first the influence of tacit knowledge between tacit knowledge into innovation and intellectual capital towards innovation (H2).The complete statement from the following is a hypothesis that there is a whole in this research:

1. $\mathrm{H}_{01}$ : Tacit knowledge do not have significant influence to Individual innovation capability.

$\mathrm{H}_{11}$ : Tacit knowledge have significant influence to individual innovation capability

2. $\mathrm{H}_{02}$ : Individual innovation capability do not have significant influence to open Innovation

$\mathrm{H}_{12}$ : Individual innovation capability have significant influence to open Innovation

\section{CONCLUSION}

Based on the stages that have been done before in this study, especially in data processing and analysts, we can conclude a few things like the following:

- SMI must pay attention to knowledge that is difficult to be codified (tacit knowledge) because this kind of knowledge is the core of innovation process in the organization. On the contrary, by not showing concerns to this type of knowledge, the knowledge will be of value only for through individual innovation capability.

- Conditions that occur in one community will give a significant influence on tacit knowledge in one SMI, so that harmonious relationships within the SMI need to be maintained. 
- The technological changes used in the SMI will have an effect on enhancing the individual's ability to innovate internally, so that SMI leaders need to prepare technology transfer in line to support innovation within its SMI.

- SMI needs to foster good cooperation with all stakeholders, because the creation of open innovation is supported by the cooperation between organization in SMI, so good network will facilitate the creation of open innovation.

In the futher research can be involved stakeholders who play a role in the process of open innovation both involved in the operational process of production and who play a role in the managerial concept, so it will be seen more clearly how knowledge has an influence on small and medium industries.

\section{ACKNOWLEDGMENT}

Authors thank to Bandung Institute of Technology and Telkom University for providing the supporting facility in conducting the research. Authors would also like to thank the owner of SMI for the opportunity given in conducting in research by providing supportive data so the research could be seamlessly conducted.

\section{REFERENCES}

[1] H. O. Kukkonen and T. Räisänen, "Innovation and knowledge-applying the 7C knowledge creation approach to innovation and re-defining innovation through social web," Department of Information Processing Science, Finland: University of Oulu, 2006.

[2] B. Hermana, Mendorong Daya Saing di Era Informasi dan Globalisasi : Pemanfaatan Modal Intelektual dan Teknologi Informasi sebagai Basis Inovasi di Perusahaan, Universitas Gunadarma, Jakarta, 2005.

[3] Z. X. Li, W. Qian, and C. Lianzhong, An Analysis of the Structure and Evaluation Methods of Individual Tacit Knowledge, Department of Management, Shenyang Institute of Aeronautical Engineering, China, 2006.

[4] H. F. Lin, "Knowledge sharing and firm innovation capability: An empirical study," International Journal of Manpower, vol. 28, no. 3, Emerald Group Publishing Limited, 2007.

[5] K. Auernhammer, M. Neumann, A. Leslie, and F. Lettice, "Creation of innovation by knowledge management: A case study of a learning software organisation", Industrial Engineering IAO, Fraunhofer Institute, 2001.

[6] K. U. Koskinen, "Evaluation of tacit knowledge utilization in work units," Journal of Knowledge Management, vol. 7, no. 5, 2003.

[7] R. Klimasauskiene, "Enchancing science-base innovation through knowledge mobility between higher education and educational practice," Kaunas University of Technology, 2003.

[8] H. Chesbrough, W. Vanhaverbeke, and J. West, Open Innovation Reasearching A New Paradigm, New York: Oxford University Press, 2006.

[9] S. Lee, G. Park. B. Yoon, and J. Park, “Open innovation in SMEs-an intermediated network model,” Reserach Policy Journal, vol. 39, pp. 290-300, 2010.
[10] B. Faust, "Implementation of tacit knowledge preservation and transfer methods," Nuclearforum Schweiz, 2007

[11] V. Ambrosini and J. Billsberry, "Person-organisation fit : An invisible hand facilitating the transfer of tacit knowledge," in Proc. Development Paper Submitted to the Strategy as Practice Track of the British Academy of Management for the 2007 Annual Conference, Warwick, pp. 1-8, 2007.

[12] D. Stenmark, "Turning tacit knowledge tangible," in Proc. of the 33rd Hawaii International Conference on System Sciences, Hawaii, U.S, 2000.

[13] S. Schwab, J. Koch, P. Flachskampf, and I. Isenhardt, "Strategic implementation of open innovation methods in small and medium-sized enterprises," in Proc. of the 2011 17th International Conference on Concurrent Enterprising, 2011.

[14] A. Rumanti, I. Wiratmadja, and T, P. Hidayat, "Analysis individual tacit knowledge toward innovation," in Proc. of IEEE International Conference Industrial Engineering and Engineering Management, Hong Kong, China, 2012.

[15] A. A. Rumanti, T. M. A. Samadhi, I. I. Wiratmadja, and R. Reynaldo, "Conceptual model of green innovation toward knowledge sharing and open innovation in indonesian SME," in Proc. International Conference on Industrial Engineering and Its Application, Nagoya, pp. 21-23, 2017.

[16] I. Ghozali, Structural Equation Modeling Metode Alternatif Dengan Partial Least Square (PLS), Badan Penerbit Universitas Diponegoro, 2006.

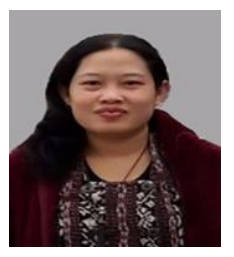

Augustina A. Rumanti was born in Surabaya, on 11th August 1980. She is a lecturer at Department of Industrial Engineering, Telkom University in Indonesia. Now she is a Ph.D student in Bandung Institute of Technology. She received her master degree from Indonesia in 2009. Her current interest researchs are in the area of organization development, knowledge management, innovation system and management of technology.

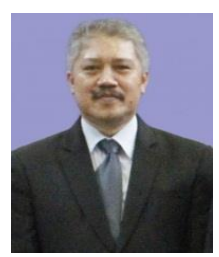

T. M. A Ari Samadhi is an associate professor at Department of Industrial Engineering, Bandung Institute of Technology in Bandung, Indonesia. He received Doctoral Degree from University of New South Wales, Australia in Production Network field. His current research interest is in technology and manufacturing system field.

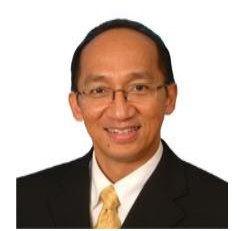

Iwan Inrawan Wiratmadja is an associate professor at Department of Industrial Engineering, Bandung Institute of Technology in Bandung, Indonesia. He received doctoral degree from Ecole Superieure des Affaire-University Pierre Mendes France, Grenoble in 1995 in management of technology field. His current research interest is in management of technology and knowledge

management field

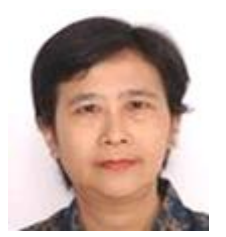

Indryati Sunaryo is an associate professor at Department of Industrial Engineering, Bandung Institute of Technology in Bandung, Indonesia. She received doctoral degree from Bandung Institute of Technology, Indonesia in 2005. Her current research interest is in human resource management. 



\section{Information Theory and Applications}


